\title{
Response Reduction of Tall Buildings subjected to Seismic Loads by Tuned Mass Damper
}

\author{
M. Umeshchandra ${ }^{1}$ and Mrs. J. Sandhya Rani ${ }^{2}$ \\ ${ }^{1}$ M. Tech. Student/CVR College of Engineering /Civil Engineering Department, Hyderabad, India \\ Email: umesh.chandra57@gmail.com \\ ${ }^{2}$ Asst. Professor/CVR College of Engineering /Civil Engineering Department, Hyderabad, India \\ Email: sandhyajaligama25@gmail.com
}

\begin{abstract}
High-rise buildings are comparatively flexible with a low damping value having greater possibilities of failure and less serviceable. Failure potential can be minimized by counteracting vibrations. Methods are available to reduce the vibration of the tall buildings. One of the methods is control of vibrations using Tuned Mass Damper. The behaviour of tall buildings is analysed by considering specific time history data along with gravity loads. The structural mass required to resist the lateral loads increase exceedingly as the level of the building goes up if the stiffness of the building is not sufficient to resist the lateral forces. The main aim of the structural engineer is to provide a suitable solution for the effects due to gravity and lateral loads, by proper usage of Lateral Load Resisting System, approximate analysis and preliminary design. In the present study, the analysis of a 25 storey structure has been done to obtain an optimum mass ratio by using passive resistance. Then by using the optimum mass ratio obtained from the analysis of 25 storey structure, the analysis of 35 and 45 -stories reinforced concrete tall buildings subjected to seismic loads has been done as per the IS codes of practice. Safety of the structure has been checked against allowable limits prescribed for joint displacements, base shear, interstorey drifts by implementing Tuned Mass Dampers (TMD). The behaviour of the building for an optimum mass ratio of Tuned Mass Damper with an increase in the height of building is found out.
\end{abstract}

Index Terms: Tall buildings, Lateral Loads, Mass ratio, Tuned Mass Damper (TMD)

\section{INTRODUCTION}

The number of Tall buildings constructed nowadays has increased. Most of these buildings have a low natural damping. So, there is a need to increase the damping capacity of a structural system in the new generation of tall and super-tall buildings. The control of vibrations induced in the buildings by seismic waves is achieved by modifying rigidities, masses, damping and shape or by providing passive or active counter forces. Some of the methods provide a possibility of improving efficiency. The selection of a vibration control device is based on a number of factors such as efficiency, compactness, weight, capital cost, operating cost, maintenance requirements and safety. Passive energy dissipation systems utilize a number of materials or devices for increasing damping, stiffness and strength. Passive energy dissipation systems are characterized by the efficiency to dissipate energy in a structure. Energy dissipation is achieved by the conversion of kinetic energy into heat or by transferring energy between vibrating modes. The latter method consists of secondary oscillators, which act as dynamic vibration absorbers.
The energy absorbed by the displacement-activated damper is through the relative displacement of the points of connections within the structure. Therefore, the behaviour is independent of the frequency of motion and the damper is in-phase with internal forces generated at the end of each vibration cycle corresponding to the peak deformations of the structure. The energy absorbed by the velocity-activated damper is through the relative velocity between the points of connection. Therefore, the behaviour depends upon the frequency of motion and the damper is out-of-phase with internal forces generated at the end of each vibration cycle corresponding to the peak deformations of the structure. Motion - Activated Dampers are secondary masses that absorb structure's vibration energy through structures' motion. They are tuned to resonate with the main structure, but remain out-of-phase with the structure. These dampers absorb the input energy of a structure and dissipate by introducing extra forces to the structure so that a less amount of energy is stored in the main structure. Table I shows the types of passive energy dampers (Chang, C. H., and Soong, T T 1980).

\section{A. Tuned Mass Dampers}

TABLE I.

TYPES OF PASSIVE DAMPERS

\begin{tabular}{|c|l|c|}
\hline $\begin{array}{c}\text { Displacement } \\
\text { Activated }\end{array}$ & $\begin{array}{c}\text { Velocity }- \\
\text { Activated }\end{array}$ & $\begin{array}{c}\text { Motion } \\
\text { Activated }\end{array}$ \\
\hline Metallic Dampers & $\begin{array}{c}\text { Viscous } \\
\text { Dampers } \\
\text { Friction Dampers }\end{array}$ & $\begin{array}{c}\text { Tuned Mass } \\
\text { Damper }\end{array}$ \\
Self-centering Dampers & Disco elastic & $\begin{array}{c}\text { Tuned Liquid } \\
\text { Damper }\end{array}$ \\
Visco elastic Dampers & & $\begin{array}{c}\text { Tuned Liquid } \\
\text { Column Damper }\end{array}$ \\
& & $\begin{array}{c}\text { Tuned } \\
\text { Sloshing Damper }\end{array}$ \\
\hline
\end{tabular}

The concept of Tuned Mass Damper came into existence in the 1940s. The spring and damping elements are secondary masses of the structure which provides a frequency dependent physical phenomenon to increase damping in the primary structure. Nowadays, numerical and experimental studies have been carried out on the effectiveness of Tuned Mass Dampers in reducing the seismic response of structures. 
Tuned Mass Damper system is a well-accepted strategy in the area of vibration control of flexible structures particularly for tall buildings. The mechanism of suppressing structural vibrations by attaching a Tuned Mass Damper to the structure is to transfer the vibration energy of the building to the Tuned Mass Damper and to dissipate the energy. In other words, the frequency of the damper is tuned to a particular structural frequency, so that when that frequency is excited, the Tuned Mass Damper will resonate out of phase with the structural motion (Den Hartog, J. P., 1947).

Properly designed tuned mass damper has the following functions:

a) Reduced displacements, accelerations, internal stresses and strains.

b) Increase structural safety. (i.e., the collapse of a building becomes less probable and hence, human life is protected).

c) Improve serviceability of the structure. (i.e., damage and corresponding repair cost in case of seismic events are reduced significantly)

\section{Classification of Tuned Mass Dampers}

Tuned Mass Dampers are divided into two groups, i.e., vertically and horizontally working devices. The application depends on the shape of the disturbing mode as well as on the position/direction of the TMD in order to reduce the vibration.

\section{i. Vertically Acting Tuned Mass Dampers}

Vertically Acting Tuned Mass Dampers are supported on helical steel springs. The frequency depends on mass and spring stiffness. The spring system is designed as a hanger system so that the springs are loaded in tension and also combined application with tension and compression springs is possible.

\section{ii. Horizontally Acting Tuned Mass Dampers}

It consists of a horizontally swinging mass, which is placed between steel springs. A damping element is arranged in parallel to the springs. The horizontal stiffness of the springs as well as the shape of the mass is responsible for the target frequencies. The flexibility is achieved by the horizontal motion of the mass at the bottom of the hanger system. The mass works in one direction only, but it may also work on the horizontal plane.

\section{Optimization of Tuned Mass Damper parameters}

The basic principles of Tuned Mass Dampers of reducing structural response are well-established, but optimal Tuned Mass Damper configuration is quite a different problem (Richard Lourenco 2011). In the design of any control device for the suppression of undesirable vibrations, the aim would be to provide optimal damper parameters to maximize its effectiveness. A typical tuned mass damper consists of a mass ' $\mathrm{m}$ ' which moves relative to the building and is attached to it by a spring with a stiffness ' $\mathrm{k}$ ' and a viscous damper with coefficient ' $c$ '.

A Tuned Mass Damper is characterized by its tuning, mass and damping ratios. The tuning ratio ' $f$ ' is defined as the ratio of fundamental frequency of the Tuned Mass Damper ' $\omega_{\mathrm{t}}$ ' to that of the building ' $\omega_{\mathrm{o}}$ '. Thus,

$$
f=\omega_{\mathrm{t}} / \omega_{\mathrm{o}}
$$

Mass ratio $\mu$ is

$\mu=\mathrm{m} / \mathrm{M}$

Where,

$\mathrm{M}$ is the total mass of a Single Degree of Freedom structure or the generalized mass of a Multi Degree of Freedom structure, computed for a unit modal participation factor.

Damping ratio is given by

$$
\begin{aligned}
& \xi=\mathrm{c} / 2 \mathrm{~m} \omega_{\mathrm{t}} \\
& \text { Time History Analysis }
\end{aligned}
$$

The Time history analysis is a step by step procedure to determine the dynamic response of a structure subjected to a specified loading that may vary with time. The analysis carried out in the present study is nonlinear.

\section{Mathematical Formulations}

\section{A. Equation of Motion for Forced Vibration Analysis of Multi Storey Plane Frame}

The equation of motion of the frame structure subjected to external dynamic force $\mathrm{p}(\mathrm{t})$ :

The dynamic response of the structure to this excitation is defined by the displacement $\mathrm{u}(\mathrm{t})$, velocity $(\mathrm{t})$ and acceleration ( $t$ ) (Ramancharla Pradeep Kumar, NPTEL). The external force is distributed among the three components of the structure.

Thus,

$\mathrm{f}_{\mathrm{S}}+\mathrm{f}_{\mathrm{D}}+\mathrm{f}_{\mathrm{I}}=\mathrm{p}(\mathrm{t})$

$f_{S}$ is the stiffness component and is associated with displacement $u$ such that

$\mathrm{f}_{\mathrm{S}}=\mathrm{ku}$

Where,

$\mathrm{k}$ is the stiffness matrix of the structure and is a symmetric matrix (i.e., $\mathrm{k}_{\mathrm{ij}}=\mathrm{kji}$ ).

$f_{D}$ is the damping component and is associated with velocity such that

$\mathrm{f}_{\mathrm{D}}=\mathrm{c}$

Where $\mathrm{c}$ is the damping matrix of the structure

$\mathrm{f}_{\mathrm{I}}$ is the mass component is associated with acceleration such that

$\mathrm{f}_{\mathrm{I}}=\mathrm{m}$

Substituting equations (2), (3) and (4) in equation (1) gives

Equation of motion:

$\mathrm{m}+\mathrm{c}+\mathrm{k} u=\mathrm{p}(\mathrm{t})$

Where,

$\mathrm{m}$ is the global mass matrix of the 2D frame structure

$\mathrm{c}$ is the global damping matrix of the frame structure (Assumed to be a zero matrix, as the damping is neglected in the structure)

$\mathrm{k}$ is the global stiffness matrix of the 2D frame structure $\mathrm{u}$ is the global nodal displacement vector

$\mathrm{p}(\mathrm{t})$ is the external force

is acceleration vector

is velocity vector

$u$ is displacement vector

Natural Frequency of the structure

$\mathrm{w}_{\mathrm{a}}=\sqrt{ }(\mathrm{k} / \mathrm{m})=\sqrt{(\text { stiffness } / \text { mass })}$

Time period $\mathrm{T}_{\mathrm{n}}=2 \pi / \mathrm{w}_{\mathrm{n}}$ 
Natural Frequency of the damper $\mathrm{w}_{\mathrm{d}}=\sqrt{ }\left(\mathrm{k}_{\mathrm{d}} / \mathrm{m}_{\mathrm{d}}\right)$

Damping of the structure $=\xi=\mathrm{c} / 2 \mathrm{mw}$

Damping of the damper $=\xi_{d}=c_{d} /\left(2 m_{d} w_{d}\right)$

Mass ratio $=\gamma=\mathrm{m}_{\mathrm{d}} / \mathrm{m}$

Frequency ratio $=\mathrm{f}=\mathrm{w}_{\mathrm{d}} / \mathrm{w}$

Amplitude ratio $=\mathrm{g}=\mathrm{w}_{\mathrm{a}} / \mathrm{w}$

\section{B. Optimum Parameters for Undamped Systems}

Harmonic main mass excitation:

f_opt $=1 /(1+\gamma)$

$\xi_{\text {d dopt }}=\sqrt{(3 \gamma /(8(1+\gamma)))}$

Harmonic base excitation:

f_opt $=1 /(1+\gamma) \sqrt{ }((2-\gamma) / 2)$

$\xi_{-}$dopt $=(\sqrt{(3 \gamma /(8(1+\gamma))))(2 /(2-\gamma))}$

Optimum parameters for damped systems:

f opt $=\left[\sqrt{ }((1-0.5 \gamma) /(1+\gamma))+\sqrt{ }\left(2-\xi^{\wedge} 2\right)-1\right]-(2.375-1.034 \sqrt{ } \gamma-$

$0.426 \gamma) \xi \sqrt{ } \gamma-(3.73-16.903 \sqrt{ } \gamma+20.496 \gamma) \xi \wedge 2 \sqrt{ } \gamma]$

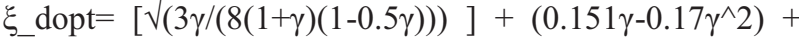

$\left(0.163 \gamma-0.498 \gamma^{\wedge} 2\right) \gamma$

Final computations of Stiffness and Damping of Damper are:

Optimum Stiffness kopt $=\gamma \mathrm{kf}$ opt $^{\wedge} 2$

Optimum Damping copt $=2 \mathrm{mw}^{-} \xi_{-}$dopt $\gamma$

\section{Model}

Analytical investigation was carried out using ETABS software for three multi-storied buildings of 25, 35 and 45 storeys are considered. A sample model of 25 storied building is shown in Figure 1.

Details of 25 Storied Symmetric Building:

(i) Material properties

$\begin{array}{ll}\text { Grade of concrete } & \text { M } 50 \\ \text { Grade of Steel } & \text { Fe } 500 \\ \text { Density of concrete } & 25 \mathrm{kN} / \mathrm{m}^{3}\end{array}$

(ii) Geometry

Each storey height $=3 \mathrm{~m}$

Plan dimensions $=8 \mathrm{~m} \times 8 \mathrm{~m}$ for each bay

No. of Bays $=10$ in $\mathrm{X}$ direction

8 in $\mathrm{Y}$ direction

(Same for $35 \& 45$ storey buildings)

(iii) Member Properties

TABLE II

FRAME SECTION PROPERTIES

\begin{tabular}{|l|c|c|c|}
\hline \multicolumn{1}{|c|}{$\begin{array}{c}\text { Frame } \\
\text { sections }\end{array}$} & $\begin{array}{c}\text { 25 Storey } \\
(\text { dimensions in } \\
\mathrm{m})\end{array}$ & $\begin{array}{c}\text { 35 Storey } \\
(\text { dimensions } \\
\text { in m })\end{array}$ & $\begin{array}{c}\text { 45 Storey } \\
(\text { dimensions } \\
\text { in m })\end{array}$ \\
\hline Beam & $0.6 \times 0.4$ & $0.6 \times 0.4$ & $0.6 \times 0.4$ \\
\hline Column & $0.85 \times 0.85$ & $0.9 \times 0.9$ & $1 \times 1$ \\
\cline { 2 - 4 } & $0.8 \times 0.8$ & $0.85 \times 0.85$ & $0.95 \times 0.95$ \\
\cline { 2 - 4 } & $0.75 \times 0.75$ & $0.8 \times 0.8$ & $0.9 \times 0.9$ \\
\cline { 2 - 4 } & $0.7 \times 0.7$ & $0.75 \times 0.75$ & $0.85 \times 0.85$ \\
\cline { 2 - 4 } & - & $0.7 \times 0.7$ & $0.8 \times 0.8$ \\
\hline $\begin{array}{c}\text { Slab } \\
\text { (Thickness })\end{array}$ & - & - & $0.75 \times 0.75$ \\
\hline
\end{tabular}

(Note: Embedded I-section in columns of size UKC152x152x37)

\section{Loading}

(i) Gravity loading

Live Load $\quad=4 \mathrm{kN} / \mathrm{m}^{2}$

Floor Finishes $=2 \mathrm{kN} / \mathrm{m}^{2}$

Ceiling load $=0.25 \mathrm{kN} / \mathrm{m}^{2}$

Ducting Load $=0.25 \mathrm{kN} / \mathrm{m}^{2}$

Wall Loads (Exterior) $=12.5 \mathrm{kN} / \mathrm{m}$

Wall Loads (Interior) $\quad=6.5 \mathrm{kN} / \mathrm{m}$

(ii) Time history loading

The time history loading is applied from earthquake data functions. Three real earthquakes data are used.

- The Chamba-1995 earthquake data file loading is used in global-X direction with 8 points per line at a time interval 0.02 seconds.

- The Chamoli-1999 earthquake data file loading is used in global-X direction with 8 points per line at a time interval 0.02 seconds.

- The N-Palm-1986 earthquake data file loading is used in global-X direction with 5 points per line at a time interval 0.005 seconds.

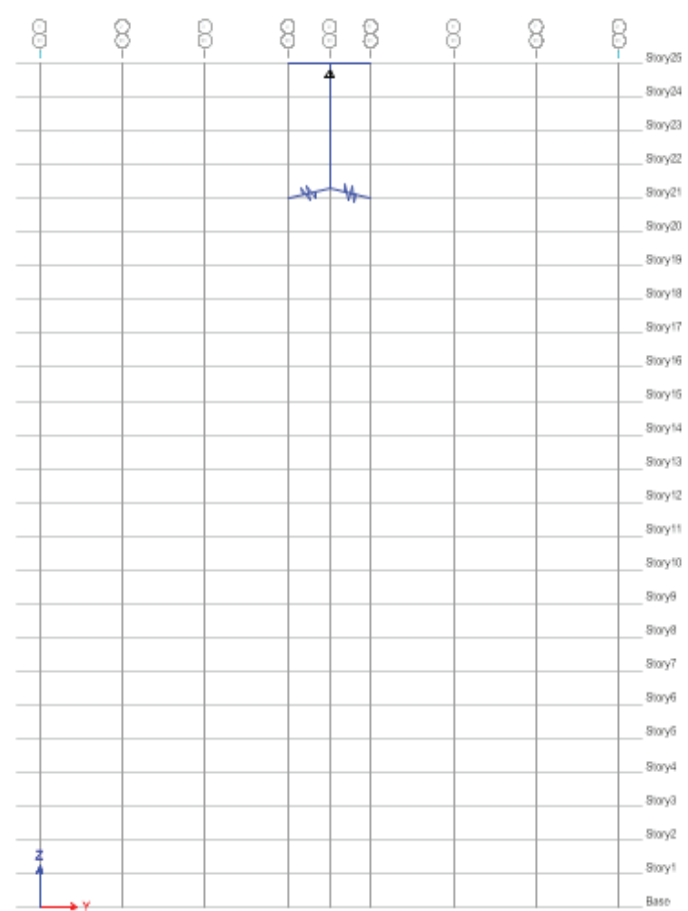

Figure 1. Elevation of the building with Tuned Mass Damper placed at centre

\section{RESULTS}

\section{A. 25 storeyed structure}

The 25-storeyed building is analyzed by using Chamba, Chamoli and N-Palm earthquake data's for finding the optimum mass ratio of the TMD So, Displacement v/s Time graphs are shown here for obtaining the optimum condition by placing the position of TMD at centre.

The results of the observations are presented as follows. 


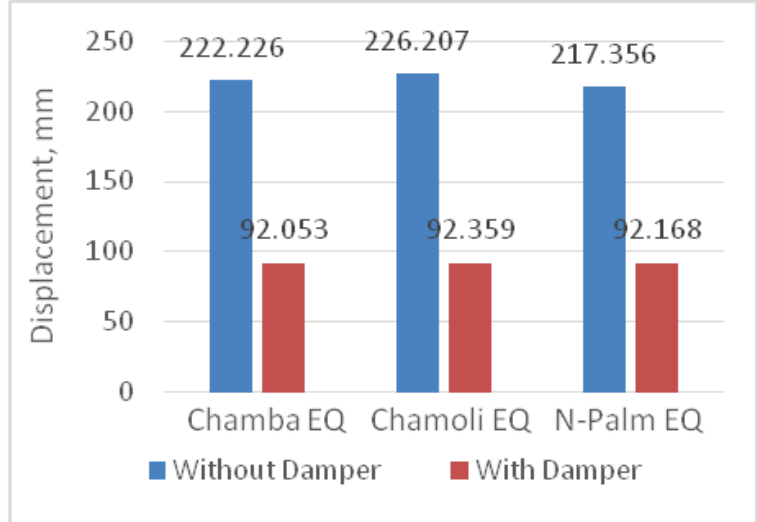

Figure 2. Joint Displacement of 25 storied building with and without Damper

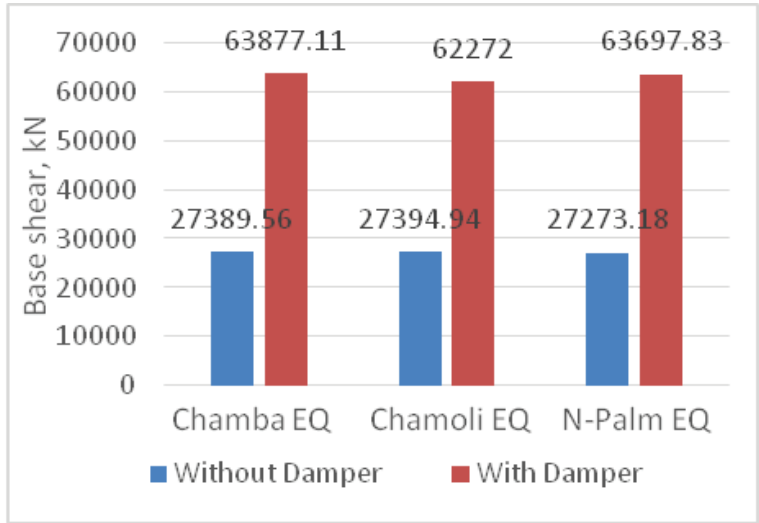

Figure 3. Base shear of 25 storied building with and without Damper

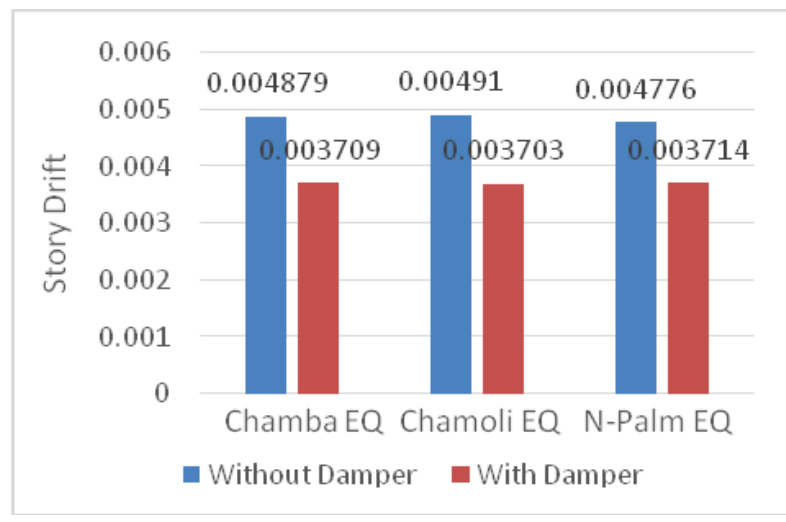

Figure 4. Storey drift of 25 storied building with and without Damper

The maximum reduction is found with $1.2 \%$ mass ratio and the storey drift is reduced by $23.98 \%, 24.65 \%$ and $22.23 \%$ with Chamba, Chamoli, and N-Palm Earthquake Data's respectively for this specified structure only. The optimum value of storey in seismic response was observed for Tuned Mass Damper is $1.2 \%$ mass ratio. So, the base shear graphs are shown for this optimum mass ratio condition by varying height of the structure i.e., for 35 and 45 storey structures with same plan area.

\section{B. 35 and 45 Storeyed Structures}

The results of the $35 \& 45$ storeyed structures are discussed below:

(a) Joint Displacement:

- Max reduction is found when TMD is placed with $1.2 \%$ mass ratio.

- The joint displacement is reduced by $60 \%$ when the TMD is placed at centre for 35- storeyed structure

- The joint displacement is reduced by $53 \%$ when the TMD is placed at centre for 45-storeyed structure.

(b) Base shear:

- For 35 storeyed building, the average increment of Base shear is found with $1.2 \%$ mass ratio and the base shear is increased by $57 \%$ when the Tuned Mass Damper is placed at centre.

- For 45 storeyed building, the average increment of Base shear is found with $1.2 \%$ mass ratio and the base shear is increased by $51 \%$ when the Tuned Mass Damper is placed at centre.

(c) Storey Drifts:

- For 35 storeyed building, the maximum reduction is found with $1.2 \%$ mass ratio and the storey drift is reduced by $20 \%$ when the Tuned Mass Damper is placed at centre.

- For 45 storeyed building, the maximum reduction is found with $1.2 \%$ mass ratio and the storey drift is reduced by $5 \%$ when the Tuned Mass Damper is placed at centre.

\section{(d) Member Forces:}

- For the 35- storeyed structure without Damper, the maximum value of Shear force was observed on the ground floor columns in the outer periphery of the building, and when Tuned Mass Damper is placed with $1.2 \%$ mass ratio, the maximum shear force was observed on the columns where the Tuned Mass Damper is placed.

- For the 45- storeyed structure without Damper, the maximum value of Shear force was observed on the ground floor columns in the outer periphery of the building, and when Tuned Mass Damper is placed with $1.2 \%$ mass ratio, the maximum shear force was observed on the columns where the Tuned Mass Damper is placed.

\section{CONCLUSIONS}

- It is found that Tuned Mass Damper can be successfully implemented as passive TMD to control vibrations of the structure subjected to earthquakes.

- Maximum response reduction was observed for the Tuned Mass Damper of 1.2\% mass ratio for 25 storeyed structure. So, the optimum mass ratio of Tuned Mass Damper is $1.2 \%$ for this configuration of building.

- For a 25 storeyed building, when the Tuned Mass Damper of mass ratio $1.2 \%$ is used, the joint displacement and storey drift are reduced up to $59 \%$ and $23 \%$ respectively and base shear is increased up to $57 \%$.

- For a 35 storeyed building, when the Tuned Mass Damper of mass ratio $1.2 \%$ is used, the joint displacement and storey drift are reduced up to $59 \%$ and $20 \%$ respectively and base shear is increased up to $57 \%$. 
- For a 45 storeyed building, when the Tuned Mass Damper of mass ratio $1.2 \%$ is used, the joint displacement and storey drift are reduced up to $53 \%$ and $5 \%$ respectively and base shear is increased up to $51 \%$.

- The columns on which the Tuned Mass Damper rests should be designed for maximum forces, as the maximum shear forces are found in Tuned Mass Damper columns when the building is subjected to seismic forces.

- The percentage reduction reduces with increase in number of storeys of the structure.

- In the present study, symmetric structures are considered. Therefore, a further scope is to study the problem using Unsymmetrical buildings.

- Behaviour of Tuned Mass Damper was studied for one position only, which provides a further scope of studying the behaviour at various positions on the roof the building.

- Comparative study of response reduction between the Tuned mass damper and Base isolators.

- Study of Fatigue behaviour of Tuned Mass Damper in the building.

\section{REFERENCES}

[1] Den Hartog, J. P., "Mechanical vibrations". McGraw-Hill, New York, N.Y., 1947.

[2] Chang, C. H., and Soong, T T, "Structural Control using Active Tuned Mass Dampers", Engineering Mechanics Division, ASCE, 106(6), pp1091-1098, 1980.

[3] Fahim Sadek, Bijan Mohrazt, Andrew W. Taylor and Riley M. Chung, "A Method of Estimating the Parameters of Tuned Mass Dampers for Seismic Applications", Earthquake Engineering and Structural Dynamics, Vol. 26, 617-635, 1997.

[4] Han-Rok Ji, Yeong-Jong Moon, Chun-Ho Kim, In-Won Lee, "Structural Vibration Control using Semiactive Tuned Mass Damper", the eighteenth KKCNN Symposium on civil Engineering - KAIST6, 2005.

[5] Richard Lourenco, "Design, Construction and Testing of an Adaptive Pendulum Tuned Mass Damper", thesis in university of waterloo, 2011.

[6] Ramancharla Pradeep Kumar, "NPTEL ONLINE COURSE Structural Dynamics Tuned Mass Damper" Earthquake Engineering Research Centre, IIT Hyderabad. 